\title{
Research on the Effective Use of Video Resources in the Rotating Class in Bohai University
}

\author{
XiaoShu Wang ${ }^{\mathrm{a}^{*}}$ and Le Wang ${ }^{\mathrm{b}}$ \\ Bohai University, Jinzhou, Liaoning, China \\ a49718990@qq.com, blewang1982@163.com
}

\begin{abstract}
Keywords: Video resources; Video acquisition; Knowledge mining; Learning initiative; Rotating class
\end{abstract}

\begin{abstract}
Video resource is an important teaching resource. The combination of video resources and learning outcome can greatly improve the students' attention and the learning initiative. This paper takes the "Standardized Management" course in Bohai University as the example, research on the students' preference of video resources, the acquisition of video resources, the show time of the video resources, the knowledge mining, and the time length of video resources. The results showed that the students' preference for video resources is diversified; students are more concerned about the video characteristics are interesting, novelty, science and technology, contemporaneity, values and clarity, students are very willing to collect and display video resources; the show time of the video resources needs to consider the characteristics of video and learning outcome; the proportion of total video time of the total time of the course should be no more than $1 / 3$, and the total length of the video should not be more than 50 minutes in each two hours class.
\end{abstract}

\section{Introduction}

With the rapid development of information technology, network resources have become a new kind of educational resources, more and more network resources applications are obtained in education. Network teaching resources include text, images, animation, audio, video and other forms, and video resources are the most vivid and infectious teaching resources. ${ }^{[1-4]}$

In the teaching process, use appropriate video resources can not only effectively solve the outdated problem of the textbook content, but also provide materials for the discussion teaching, the research teaching and the exploring learning, and more importantly, video resources can greatly improve students' attention, make students think consciously, improve students' curiosity and learning initiative. [5-10]

At present, video resources have been widely used in teaching activities, and achieved good results, but there are still several problems that need to be solved. First, what are the characteristics of video resources that students prefer? Second, how to get the latest and high-quality video resources? Third, what is the best time to show the video resources? Fourth, how to excavate the important information form the video? Fifth, what is range of time length of the video.

\section{The Connotation of Rotating Class}

The implementation of rotating class in Bohai University is starting in 2013, rotating class including the first class and the second class. The first class is in the charge of course teacher, focusing on improving students' innovative thinking. The second class is in the charge of undergraduate tutor, focusing on improving students' practical ability by activities participation.

The first class is divided into classroom teaching and extra-curricular teaching, the classroom teaching accounts for $60 \%$ of program hours, and extra-curricular teaching accounts for $40 \%$. During the classroom teaching, $60 \%$ of the time is the teacher's explanation, $40 \%$ of the time is classroom interaction. During the extra-curricular teaching, $60 \%$ is question time, and $40 \%$ is after class instruction. 
The rotating class has significantly improved the freedom of curriculum arrangements; enhance the initiative of students learning. The classroom interaction also provides sufficient time for video resources utilization.

\section{The Utilization of Video Resources in the Rotating Class}

Many teachers have carried out the practice of video teaching in Bohai University, this paper takes the "Standardized Management" course as the example, after a semester of video practice, conducted a questionnaire on 118 students, and the main conclusions are as follows:

Students' Preference for Video Resources. Students' preference for video resources include content, theme, age, country, language, sound effects, characters, colors, interesting, novelty, science and technology, clarity, values and so on. The survey shows that students have no special requirements on the theme, age, sound effects, characters, colors and other aspects. Students are more concerned about the video characteristics are interesting, novelty, science and technology, contemporaneity, values and clarity. (Fig .1)

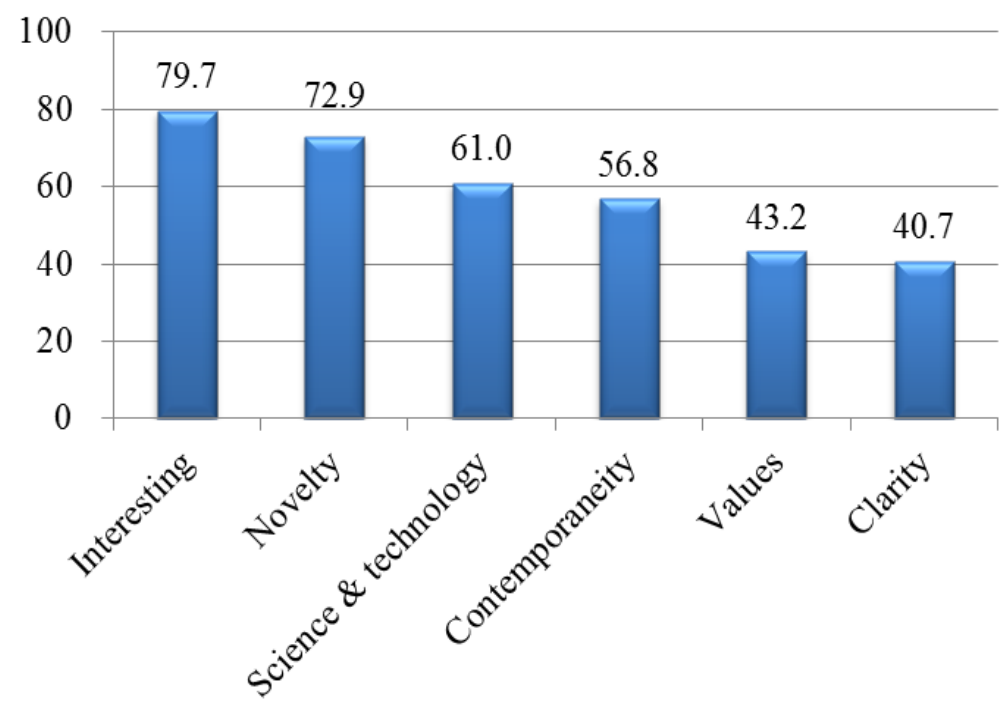

Figure 1. Students' preference for video resources (\%)

We ask students to list the videos that they can remember and favorite, the most popular videos are listed in Table 1, these videos are all novel, knowledgeable and strong impact, that are consistent with the findings of the video characteristics discussed above.

Table 1 Students' favorite videos in the "Standardized Management" course

\begin{tabular}{|l|l|}
\hline Rank & Video \\
\hline 1 & National Geographic: Ultimate Factories: Coca Cola \\
\hline 2 & MINI Car Branding \\
\hline 3 & National Geographic: Mega Structures: Dubai's Dream Palace \\
\hline 4 & BMW Production Line \\
\hline 5 & 3D Print News \\
\hline 6 & Samsung Mobile Evolution \\
\hline 7 & The Water Cube \\
\hline 8 & Jingdong Logistics \\
\hline 9 & Boeing 737 Production Line \\
\hline 10 & Corning Glass Branding \\
\hline
\end{tabular}


In the feature of country, only $16.1 \%$ of the students prefer the domestic videos, $30.5 \%$ of the students prefer foreign videos, $53.4 \%$ of the students choose indifferent. In the feature of language, $39.8 \%$ of the students prefer Chinese, only $9.3 \%$ of the students prefer foreign languages, $50.9 \%$ of the students choose indifferent. But if the video is in foreign language, $97.5 \%$ of the students need a Chinese subtitle for better understanding.

Acquisition of Video Resources and Establishment of Video Resource Database. Internet has a large number of video resources, there are a lot of opinions, but it also means that to find the right quality video is not easy.

At the beginning of the semester, the "Standardized management" teaching team analyzed the textbook and syllabus, determined the video search direction of each chapter, then based on the core words, find out the related words, then carry out the specific search combined with the practice of typical industries or well-known enterprises. Search sites are mainly Youku, Storm Video, Ten cent Video, Sohu video, Baidu video and so on, the main download tools are FLVCD, Youku Client, and Ten cent Video and so on, among them, and FLVCD supported the most websites. After the completion of the video download, comparative analysis, select several appropriate videos for each chapter, finally establish the course video resource database. During the semester, teaching team also acquires current events video and other wonderful videos, and adds these videos to the video resource database, make it dynamically update.

On the other hand, students can also participate in the acquisition of video resources. There are a lot of students, even each student finds a few videos, and the course will also have a lot of videos. These videos can be showed and explained by students in class, and also can be used as auxiliary materials for after class learning.

The survey shows that $67.8 \%$ of the students would like to download their own videos, $16.9 \%$ of the students are not sure, and only $15.3 \%$ of the students are unwilling. $65.3 \%$ of students are willing to show and explain their own videos, $27.1 \%$ of students are not sure, and only $7.6 \%$ of the students are unwilling.

After a semester of accumulation, the "Standardized Management" course video resource database has accumulated 140 high-quality video, including factory workshop, automobile, construction engineering, advanced technology, quality management, conformity assessment, modern logistics and others, and covers almost all important knowledge points of "Standardized Management" courses. In every two hours of teaching, the teaching team can show many corresponding wonderful videos.

Show Time of Video Resources and Knowledge Mining. Video resource show time can be divided into three ways, before instruction, during instruction and after instruction. Before instruction is show the video first, then explain the course knowledge. During instruction is show the video while explaining knowledge, alternate video and knowledge. After instruction is instruction first, then show the video to consolidate. Three ways obviously have their pros and cons. The survey shows that students are more like before instruction and after instruction (Fig .2)

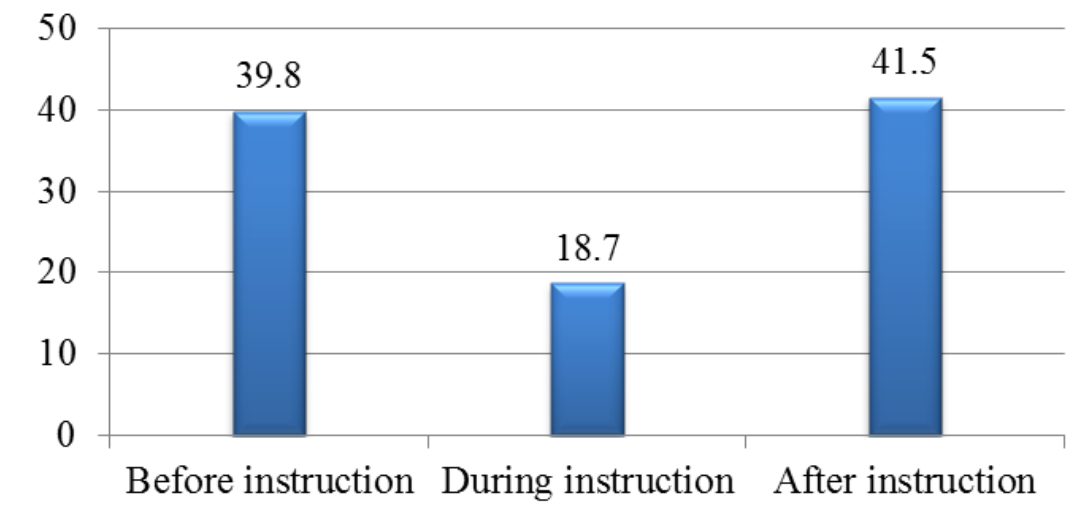

Figure 2. Students' preference for video show time (\%) 
The students don't want suffer the repeatedly interrupted in the video show, and the knowledge points also seemed fragmented, impact the students' continuous thinking. The teaching team found that the video show time also related to the video characteristics, the short videos and interesting videos appropriate for before instruction, the long videos and theoretical videos are appropriate for after instruction.

The knowledge mining of video is also a very important issue, if the teachers only show the video but without any analysis, it is obviously a waste of resources. Actually, many questions can be asked after the video show time, such as what does the video show about the course? How to solve the similar problems in the video? Is there a better solution than the video shows? In this process, the teacher can use group discussion, teacher-student interaction, scene reproduction and other activities, let more students participate in interaction, inspire students to think and discuss, and acquire more knowledge.

Time Length of Video Resources. As the course time is limited, the total time of video show should be moderate. Too much video will have a negative effect.

The survey shows that, in the proportion of total video time of the total time of the course, $6.8 \%$ of the students think should be accounted for no more than $1 / 10$ of total hours, $16.1 \%$ of the students think should be accounted 1/10 1/5, 40.7\% of the students think should be accounted 1/5 1/3, 32.2\% of the students think should be accounted 1/3 1/2, 4.2\% of the students think should be over $1 / 2$. Therefore, the proportion of total video time of the total time of the course should be no more than $1 / 3$.

In each two hours class, the total video time should be no more than 50 minutes. And over $95 \%$ of the students want to see less than 5 videos, if not, may forget the important knowledge. For a single video, the time length can be very different, but more than $70 \%$ of students believe that the video time should not exceed 40 minutes, otherwise will feel tired and boring.

\section{Notices in the Utilization of Video Resources}

First, the video search and download must focus on the course knowledge points. Second, the teachers should save the time of search and download video, they should pay more attention to the course knowledge system. Third, the teachers should avoid the repeated show of the same video in different courses. Forth, the teachers should respect video copyright. Teachers have the right to use video for teaching and research, but must indicate the original or copyright owner of the video, and prohibit sell and publish for money.

\section{Summary}

This paper takes the "Standardized Management" course as the example, analysis the effective use of video resources in the rotating class in Bohai University. The result shows that, video resources can significantly improve classroom atmosphere, improve students' attention and learning initiative, enhance students' self-confidence and sense of achievement, and directly improve the teaching effect.

\section{Acknowledgements}

This research was supported by the University Basic Scientific Research Foundation of Department of Education of Liaoning Province "Research on the mechanism and countermeasures of enhancing teachers' sense of responsibility and improving teachers' professional ability (WY2016007)”.

\section{References}

[1] N.H. Lee, D. Yeo, S.E. Hong: ZDM, Vol.46 (2014) No.3,p.465-480.

[2] K.Roy: Science Scope, Vol.32 (2009) No.7,p.78-79.

[3] P. Laurenson, K. Mcdermott, K. Sadleir, D. Meade: English in Education, Vol.49 (2015) No.1,p.5-24. 
[4] M. Mulholland, U. O'Connor: International Journal of Inclusive Education, (2016) No.20,p.1-14.

[5] B. Shindler, J. Hino, R. Gordon: Journal of Forestry, Vol.103 (2004) No.1,p.41-46.

[6] W.M. Jackman, P. Roberts: Journal of Educational Technology Systems, Vol.42 (2014) No.3, p.273-297.

[7] H.Z. Waring, D. Yu: Language Learning Journal, (2016) No.1, p.1-12.

[8] A. Zakharov, G. Tsheko, M. Carnoy: International Journal of Educational Development, (2016) No.50, p.108-124.

[9] K. Danielsson: Linguistics \& Education, (2016) No.35, p.88-99.

[10]C.F. Herreid, N.A. Schiller: Journal of College Science Teaching, Vol.42 (2013) No.5, p.62-66. 